\title{
Foxp2 Mediates Sex Differences in Ultrasonic Vocalization by Rat Pups and Directs Order of Maternal Retrieval
}

\author{
J. Michael Bowers, ${ }^{1}$ Miguel Perez-Pouchoulen, ${ }^{4,5}$ N. Shalon Edwards, ${ }^{3}$ and Margaret M. McCarthy ${ }^{1,2,3}$ \\ Departments of ${ }^{1}$ Physiology and ${ }^{2}$ Psychiatry, and ${ }^{3}$ Department of Pharmacology and Program in Neuroscience, University of Maryland School of Medicine, \\ Baltimore, Maryland 21201, and ${ }^{4}$ Centro de Investigaciones Cerebrales and 5 Doctorado en Neuroetología, Universidad Veracruzana, 91000 Xalapa, México
}

The FOXP2 gene is central to acquisition of speech and language in humans and vocal production in birds and mammals. Rodents communicate via ultrasonic vocalizations (USVs) and newborn pups emit distress USVs when separated from their dam, thereby facilitating their retrieval. We observed that isolated male rat pups emitted substantially more USV calls and these were characterized by a significantly lower frequency and amplitude compared with female rat pups. Moreover, the dam was more likely to first retrieve male pups back to the nest, then females. The amount of Foxp2 protein was significantly higher in multiple regions of the developing male brain compared with females and a reduction of brain Foxp2 by siRNA eliminated the sex differences in USVs and altered the order of pup retrieval. Our results implicate Foxp2 as a component of the neurobiological basis of sex differences in vocal communication in mammals. We extended these observations to humans, a species reported to have gender differences in language acquisition, and found the amount of FOXP2 protein in the left hemisphere cortex of 4-year-old boys was significantly lower than in age-matched girls.

\section{Introduction}

Effective communication between conspecifics is essential to fitness at both the individual and species level. Bird song has proven particularly valuable because of the profound sex differences exhibited by some species, leading to the discovery of the first sexually dimorphic neuroanatomical underpinnings controlling a specific behavior (Nottebohm and Arnold, 1976). Sex differences in auditory communication are prevalent in the animal kingdom (Kelley and Bass, 2010) but to date they have largely if not exclusively been identified in the context of attracting conspecific mating partners and/or defending territories. An additional critical communicative pair is the parent/offspring unit. When dependent offspring are separated from their caregiver they frequently signal their distress vocally. This is a tightly regulated contextspecific behavior that is common in a wide range of vertebrate species including birds, rodents and humans (Bell and Ainsworth, 1972; Vilberg et al., 1984; Brudzynski, 2005). To our knowledge, there has been no consideration of whether male versus female dependents signal differently, and if so, whether this has any functional consequences.

FOXP2 is a member of the forkhead family of transcription factors and has a highly conserved amino acid and DNA sequence

\footnotetext{
Received Jan. 30, 2012; revised Dec. 6, 2012; accepted Dec. 7, 2012.

Author contributions: J.M.B. and M.M.M. designed research; J.M.B., M.R.P.-P., and N.S.E. performed research; M.M.M. contributed unpublished reagents/analytic tools; J.M.B. and M.R.P.-P. analyzed data; J.M.B. and M.M.M. wrote the paper.

This work was supported by NIH Grant R01 NS050525 to M.M.M., NIH Individual Postdoctoral Fellowship (F32) MH086258 to J.M.B., and Consejo Nacional de Ciencia y Tecnología (CONACYT 205779) of Mexico to MPP. Human tissue was obtained from the NICHD Brain and Tissue Bank for Developmental Disorders at the University of Maryland, Baltimore, Maryland.

Correspondence should be addressed to Dr. J. Michael Bowers at the above address. E-mail: mbowe006@umaryland.edu.

DOI:10.1523/JNEUROSCI.0425-12.2013

Copyright $\odot 2013$ the authors $\quad 0270-6474 / 13 / 333276-08 \$ 15.00 / 0$
}

as well as conserved distribution in the brain across a wide range of species that have some component of vocal communication (Fisher and Scharff, 2009). In humans, FOXP2 was found to diverge from a common ancestor with chimpanzees as observed by a two amino acid switch in its sequence (Enard et al., 2002). This switch in the sequence of FOXP2 has recently been found to be shared with Neanderthals as well (Krause et al., 2007; Ptak et al., 2009). Moreover, as a transcription factor, Foxp 2 regulates both the repression and expression of a large number of genes, many of which are associated broadly with brain patterning and specifically with neurite outgrowth, dendritic branching, and axonal morphology (Schulz et al., 2010; Mukamel et al., 2011; Vernes et al., 2011). The closely related FOXP1 forms heterodimers with FOXP2, and the relative ratio of FOXP2 to other FOXP transcription factors may serve as a determinant of transcriptional repression versus activation (Li et al., 2004).

Mutations in the human FOXP2 gene produces devastating language and speech impairments, as in the extended KE family (Lai et al., 2001), and in other families similarly affected with childhood apraxia of speech (MacDermot et al., 2005). Variants in other genes have been linked to stuttering (Newbury and Monaco, 2010), and language deficits in autism as well as specific language impairment (Vernes et al., 2008). In zebra finch songbirds FoxP2 levels increase during the period of song development (Teramitsu et al., 2010), and chronic reduction of Foxp2 expression with viral transfection of siRNA directed against the mRNA reduces dendritic spines on striatal neurons (Schulz et al., 2010). Birds with reduced FoxP2 expression cannot effectively imitate their tutors and have more variable song (Haesler et al., 2007). These complex and multifactorial effects of changes in Foxp2 levels or functionality reflect its ability to both repress and activate the transcription of large numbers of interrelated genes (Konopka et al., 2009). The purpose of the current study was 

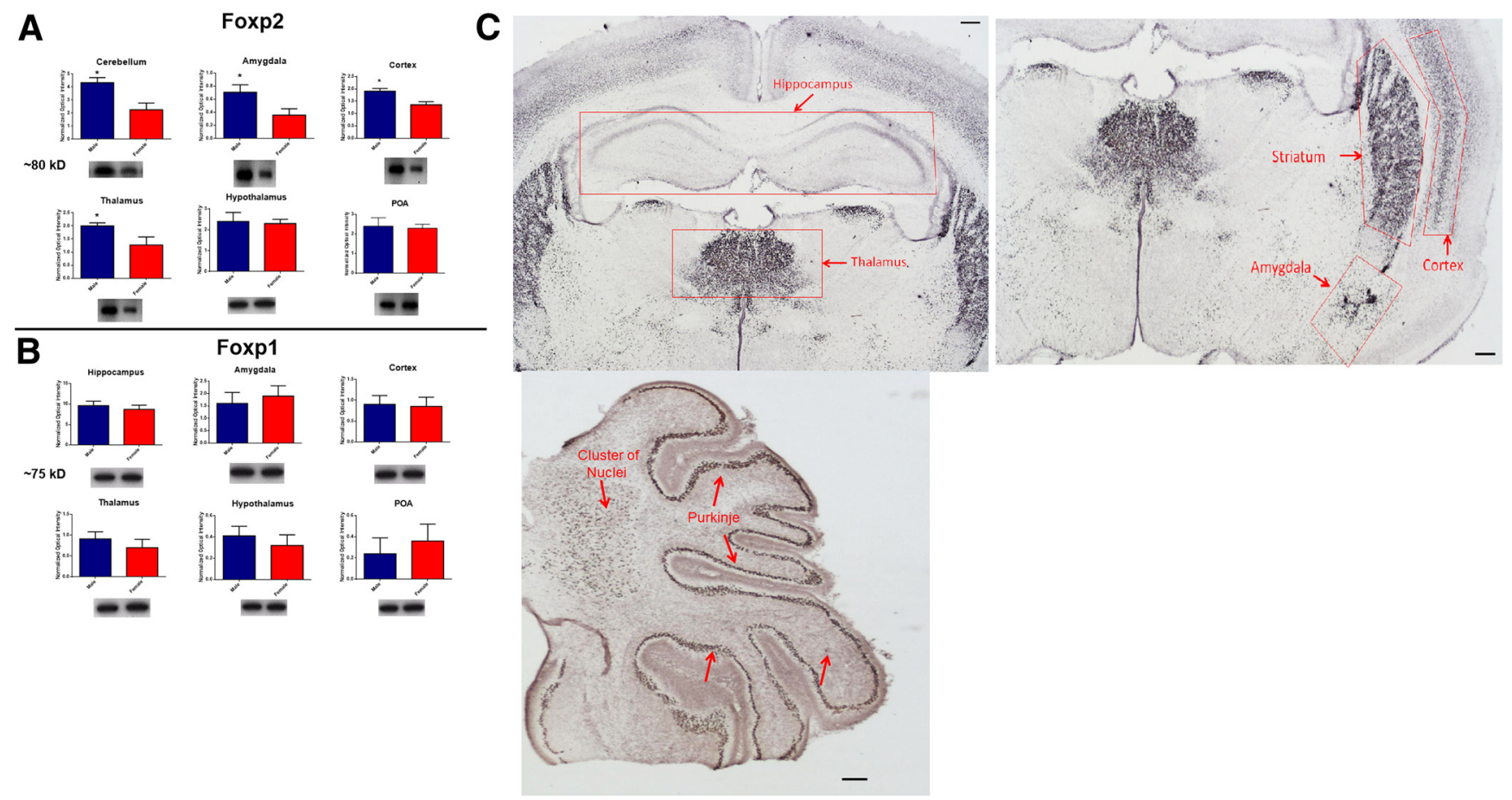

Figure 1. Male pups have higher levels of Foxp2 protein. The relative amount of Foxp2 protein was quantified in tissue collected from the cerebellum, amygdala, cortex, thalamus, hypothalamus and POA at $4 \mathrm{~d}$ of age. $A$, Males had significantly more Foxp2 than females in every brain region except the hypothalamus and POA, two brain regions closely associated with reproduction but not vocal communication. Data are expressed as mean ( \pm SEM), $n=7-8$ /group, significant sex difference $\left({ }^{*} p<0.05, t\right.$ test). $\boldsymbol{B}$, In these same animals, basal levels of Foxp 1 protein were not sexually dimorphic in any examined brain region. C, Photomicrographs of a PN4 female showing Foxp2 expression in key brain regions known to express Foxp2 as well as the hippocampus which shows no positive staining. Scale bar, $50 \mu \mathrm{m}$.

twofold; first, to determine whether there are identifiable quantitative sex differences in rat pup ultrasonic distress calls and, if so, what mediates that sex difference; and second, to determine whether the dam perceives the sex difference and alters her behavior accordingly.

\section{Materials and Methods}

Subjects. Timed pregnant Sprague Dawley rats purchased from Harlan Labs were allowed to deliver normally under standard laboratory conditions. The morning that pups were found in the nest was designated as the day of birth (PN0). Each pup was identified on PNO by injection of India Ink into the footpad using a 30-gauge needle. The animals were housed in polycarbonate cages $(20 \times 40 \times 20 \mathrm{~cm})$ with corncob bedding under a reverse $12 \mathrm{~h}$ light/dark cycle. Food and water were available ad libitum. The University of Maryland, Baltimore Institutional Animal Care and Use Committee approved all animal procedures.

Human tissue samples. Fresh-frozen human cortex samples from boys and girls were obtained from the University of Maryland Brain and Tissue Bank. Demographics on the male tissue samples are as follows: 5 males, all of whom were Caucasian. The postmortem interval range was 15-19 $\mathrm{h}$ and the mean age was 4 years $196 \mathrm{~d}$, with an age range of 4 years $5 \mathrm{~d}$ to 5 years $114 \mathrm{~d}$. For the female tissue samples there were 5 females: 1 Caucasian, 3 African American, and 1 Asian. The postmortem interval range was $12-24 \mathrm{~h}$ and the mean age was 4 years $268 \mathrm{~d}$, with an age range of 3 years $347 \mathrm{~d}$ to 5 years $34 \mathrm{~d}$. All donor tissue was free of disease or infection. In all cases, the cause of death was due to accident. The cortex samples were all from the left hemisphere and taken from Brodmann's area 44.

Western blot analysis. PN2 and PN4 rat pups were killed by rapid decapitation, and brain tissue was dissected and processed for Western blot analysis by methods similar to those in previously published reports (Amateau and McCarthy, 2002). The human brain tissue was already dissected and flash frozen before we obtained it and was processed following the same protocol used with the rat brain tissue. All membranes were blocked in $10 \%$ nonfat milk protein (Bio-Rad) for $1.5 \mathrm{~h}$ and then incubated in the primary antibody, anti-Foxp2 (1:2500; Abcam) or anti-
Foxp $1(1: 3000, \mathrm{Abcam})$ for $24 \mathrm{~h}$ at $4^{\circ} \mathrm{C}$. Following a $30 \mathrm{~min}$ incubation in anti-rabbit HRP-linked secondary antibody (1:3000; Cell Signaling Technology), the immunoreactive bands were detected using chemiluminescence (Phototope HRP Western blot Detection System, LumiGLO Reagent and peroxide, Cell Signaling Technology). The membranes were then incubated in a Ponceau $S$ (Sigma) stain and the density of the largest band on the membrane, which includes $>200$ proteins, was used as a loading control. For human tissue samples, GAPDH was used as the loading control because the amount of protein loaded was considerably higher $(220 \mu \mathrm{g})$, compared with the rat tissue $(15 \mu \mathrm{g})$, resulting in saturation of the blot after Ponceau staining and a loss of linearity in the signal. The protein of interest was detected as a band with a relative molecular mass of $\sim 80 \mathrm{kDa}$ (Foxp2) or $\sim 75 \mathrm{kDa}$ (Foxp1) or $\sim 37 \mathrm{kDa}$ (GAPDH). The integrative grayscale pixel area-density was captured using a CCD72 camera (MTI), and analyzed with National Institutes of Health ImageJ software.

Ultrasonic vocalization recordings. Vocal emissions were recorded for 5 min using PN4 pups that were isolated from maternal interaction. Ambient temperature was maintained at $22^{\circ} \pm 1^{\circ} \mathrm{C}$. On the day of testing, all pups were placed in a handmade sound attenuating, Plexiglas container (width, $15 \mathrm{~cm}$; height $15 \mathrm{~cm}$ ) and recorded for $5 \mathrm{~min}$. All recordings were obtained using an UltraSoundGate Condenser Microphone (CM16; Avisoft Bioacoustics) placed at a fixed height of $20 \mathrm{~cm}$ above the pups. The microphone was connected via an Avisoft UltraSoundGate 416 USB Audio device connected to a personal computer. Acoustic data were recorded with a sampling rate of $300,000 \mathrm{~Hz}$ in 16 bit format. For acoustical analysis, recordings were transferred to SASLab Pro (version 5.10; Avisoft Bioacoustics), and a fast Fourier transform was conducted (512 FFT length, $100 \%$ frame, Hamming window and $75 \%$ time window overlap). An automated threshold-based algorithm (threshold: $-50 \mathrm{~dB}$ ) and a hold time mechanism $(5 \mathrm{~ms})$ were used to detect ultrasonic vocalizations (USVs). A high-pass finite impulse response filter was used to eliminate background noise below $20 \mathrm{kHz}$. Calls were also inspected manually to ensure that all USVs detected using the software's automatic processing algorithms were legitimate calls. All false signals were removed before 
A
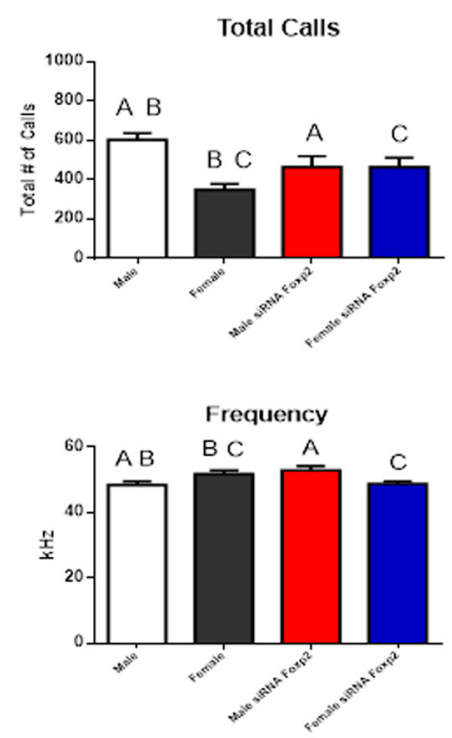

Amplitude

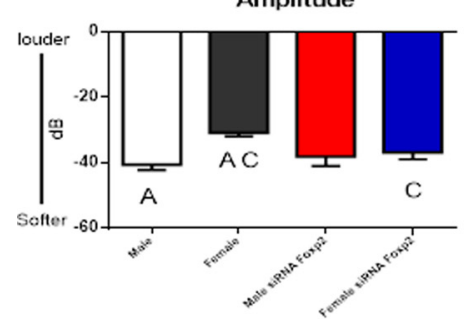

B
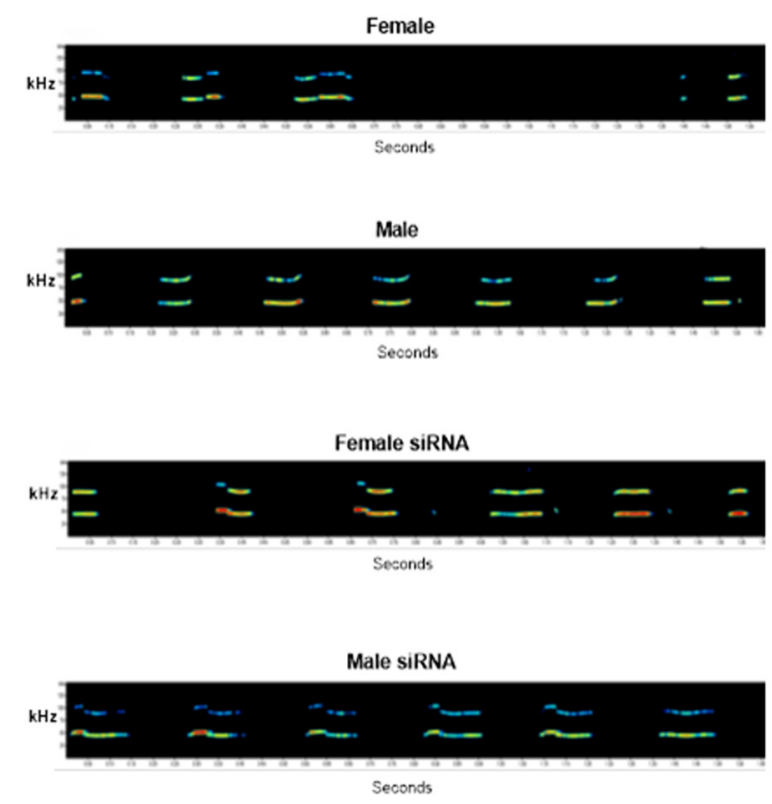

Total Calls

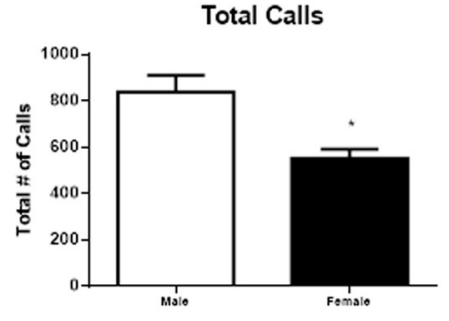

Frequency

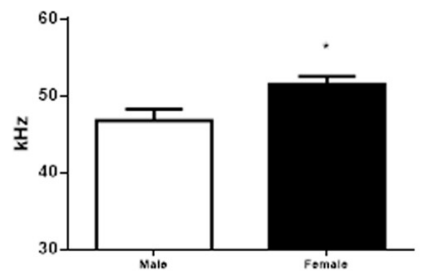

Amplitude

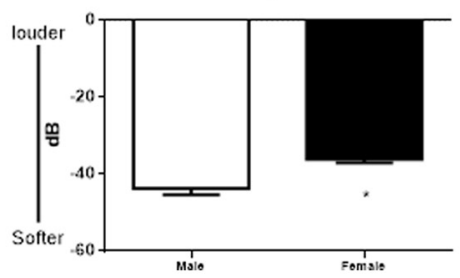

Figure 2. Male pup ultrasonic vocalizations are different from female pup vocalization and Foxp2 siRNA reverses this pattern. $A$, Infusion with siRNA or scrambled control RNA to 4-d-old pups resulted in control treated males making almost twice as many distress USVs per unit time as control treated females. The mean frequency and amplitude of the calls are significantly lower in males compared with their female littermates (two-way ANOVA; $p<0.05$ ). Treatment with siRNA directed against Foxp2 mRNA $2 \mathrm{~d}$ before testing significantly reduced the total number of calls in males but increased the number in females. The same pattern was seen for frequency whereas amplitude was modified by siRNA treatment only in females $(F$ test; $p<0.05)$. Data are expressed as mean ( \pm SEM) of calls, $n=8$ /group. Groups with the same symbol are significantly different from each other. $B$, Typical sonograms of USVs from a control female (top), siRNA Foxp2-treated female, control male and siRNA Foxp2-treated male (bottom). C, Noninjected controls were not different from the scrambled injected controls ( $t$ test; $p>0.05, n=8 /$ group).

statistical analysis was performed. Various call parameters were quantified, including fundamental mean frequency, fundamental mean amplitude, frequency bandwidth ( $\max -\min$ frequency), duration, and number of calls emitted. All sonograms shown for each of the respective sex and treatment conditions were randomly selected. The sonograms displayed in the figures were obtained from the start of the second minute of the $5 \mathrm{~min}$ audio recording session. All sonograms were $1.6 \mathrm{~s}$ in length. The investigators conducting USV analyses were blind to the experimental condition and sex of the pups. Rat pups used for USV recordings were not the same pups used for the Western blot analysis.

In vivo siRNA treatment. Bilateral intracerebroventricular (ICV) injections were performed under cryoanesthesia. A 23 gauge $1 \mu$ l Hamilton syringe attached to a stereotaxic manipulator was placed $1 \mathrm{~mm}$ caudal to bregma and $1 \mathrm{~mm}$ lateral to the midline. The syringe was lowered $3.0 \mathrm{~mm}$ into the brain and then backed out $0.5 \mathrm{~mm}$. One microliter of Foxp2 siRNAs or scrambled missense control vehicle was infused over $60 \mathrm{~s}$. The dose of the siRNA was $20 \mu \mathrm{g} / \mu \mathrm{l}$. After the infusion, the syringe remained in place for $2.5 \mathrm{~min}$, and then the procedure was repeated on the other hemisphere. ICV injections were done on PN0 and PN1. The Foxp2 siRNA was custom designed and synthesized specifically for the rat (Invitrogen: catalog \# RSS 365192). The negative control siRNA consisted of a scrambled sequence that does not lead to specific degradation of any known cellular mRNA. The primer length was $25 \mathrm{bp}$ and the sequence was 5' -CAGCAGCAAACAAGUGGAUUGAAAU-3' (sense strand) and 5'-AUUUCAAUCCACUUGUUUGCUGCUG-3' (antisense strand).

In vitro siRNA transfection of primary neuronal cell cultures. On PN0, the striatum and cortex from mixed sex cultures $(n=10)$ was microdis- sected and placed into $2 \mathrm{ml}$ of HBSS and digested with $500 \mathrm{ml}$ of $0.25 \%$ trypsin (Invitrogen) and $250 \mathrm{ml}$ of $1 \%$ DNASE for $15 \mathrm{~min}$ at $37^{\circ} \mathrm{C}$. The supernatant was removed, and cells were washed twice with HBSS and triturated in Neurobasal-A (Invitrogen), 5\% fetal bovine serum (Invitrogen), and $1 \%$ antibiotic/antimycotic (Invitrogen) until dissociated. Cell density and viability were determined on a hemacytometer using Trypan blue, and cells plated at 250,000 cells/slip at a $100 \mathrm{ml}$ volume on $2.5 \mathrm{~cm}$ round polylysine-treated glass coverslips in $3.5 \mathrm{~cm}$ Petri dishes. After allowing cells to seed for $2 \mathrm{~h}$, cultures were fed with $2 \mathrm{ml}$ of cell culture medium, and allowed to acclimate and grow for $48 \mathrm{~h}$ before transfection using FuGENE 6 (Roche) transfection reagent following manufacturer protocols. Two micrograms of RNA following a 3:2 transfection ratio of RNA to FuGENE were used for transfection. Twenty-four hours after transfection, cell cultures were harvested and processed for Western blot analysis as described above.

Quantitative real-time PCR. RNA was prepared from frozen human brain tissue samples using QIAzol and purified on RNeasy columns following manufacturer's protocols (Qiagen). We used $0.1 \mathrm{~g}$ of human tissue per sample. RNA was transcribed to cDNA using the Transcriptor First Strand cDNA Synthesis Kit (Roche Applied Science) using both oligo-dT and random primers. A quantity of 1.2-5.0 mg was used in a reaction to synthesize cDNA with oligo-dT primers. Quantitative realtime PCR was performed on an ABI ViiA 7 (Applied Biosystems) with ViiA 71.2 software. Quantitative real-time (qRT)-PCR was performed with an annealing temperature of $60^{\circ} \mathrm{C}$, using Power SYBR Green Master Mix (Applied Biosystems). Primers specific for candidate gene (FOXP1) and for the control housekeeping gene (RpL13A) were designed using 

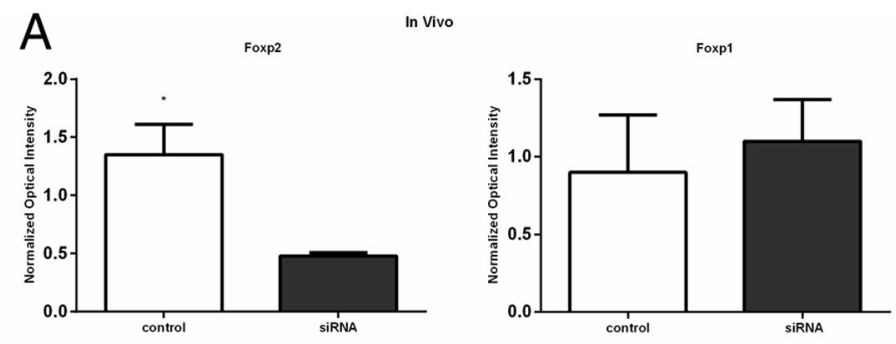

C PN4
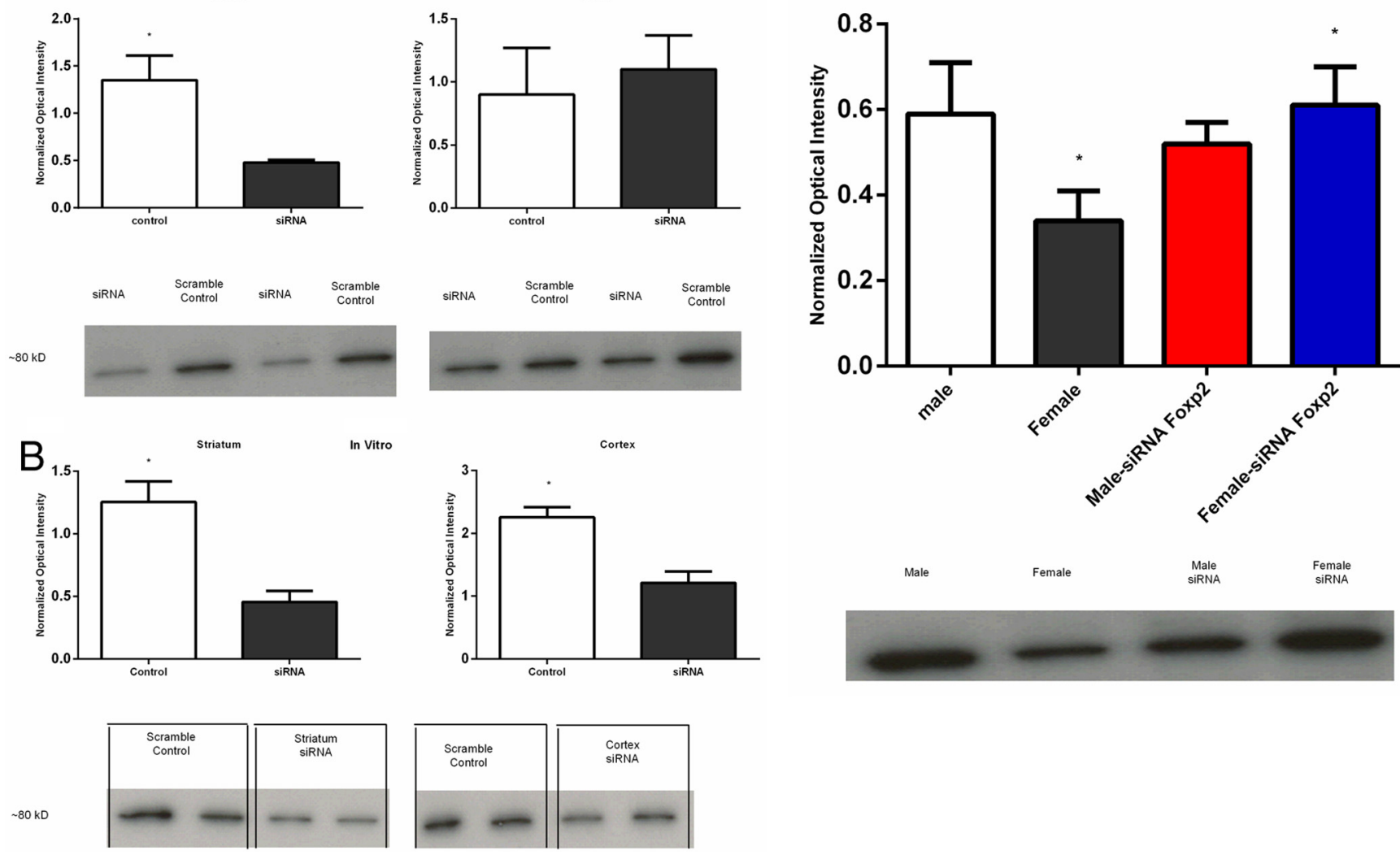

Figure 3. SiRNA against Foxp2 was effective at reducing protein levels both in vivo and in vitro. $A$, I $n$ vivo infusion of siRNA directed against Foxp2 $m R N A$ on the day of birth and the subsequent day significantly reduced Foxp2 protein levels $24 \mathrm{~h}$ later but had no impact on the closely related Foxp1 $(F<1.0, p>0.05)$. $N=2-3$ /group with equal numbers of males and females. $\boldsymbol{B}$, In vitro transfection of primary cell cultures on DIV 3 with siRNA directed against Foxp2 $\mathrm{mRNA}$ reduced Foxp2 protein levels in both the cortex and striatum. $C$, By postnatal day 4 , we again confirmed a sex difference in Foxp2 protein levels, with males having higher levels than females, and the suppression of Foxp2 levels by siRNA was no longer apparent in males $(F<1.0, p>0.05)$. However, females treated with Foxp2 siRNA showed an increase in Foxp2 protein compared with scrambled control treated females, suggesting a rebound following inhibition $(F$ test; $p<0.05), n=8 /$ group with equal numbers of males and females). Groups with the same symbol $(*)$ are significantly different from each other.

PrimerBank 0.34. Human FOXP2 primers used were as follows: forward 5'-TTGGATGACCGAAGCACTG-3' and reverse 5'-AGGTTTGGGA GATGGTTTGG-3'. Primers for the control gene used were (RpL13A): forward $5^{\prime}$-TGTTTGACGGCATCCCAC-3' and reverse $5^{\prime}$-CTGT CACTGCCTGGTACTTC-3'.

Immunohistochemistry. Free-floating tissue sections from PN4 pups were rinsed with $0.1 \mathrm{M}$ PBS, incubated with $3 \%$ hydrogen peroxide in PBS for $30 \mathrm{~min}$, and then rinsed. Sections were coincubated with 10\% BSA in $0.4 \%$ Triton X-100 (PBS-T) for $60 \mathrm{~min}$ at room temperature (RT) and then for $48 \mathrm{~h}$ at $4^{\circ} \mathrm{C}$ using a polyclonal antibody against Foxp2 in PBS-T (1:5000, Abcam). Sections were rinsed in PBS and incubated with biotinylated anti-rabbit secondary (1:800, Vector Labs) in PBS-T for $90 \mathrm{~min}$ at RT. Sections were rinsed in PBS and then incubated in Vectastain Elite $\mathrm{ABC}$ reagents (1: 1000, Vector Labs) in PBS-T for $1 \mathrm{~h}$. Foxp2-positive cells were detected with nickel-diaminobenzidine as chromagen, creating a dark purple color in Foxp2-positive nuclei.

Statistical analyses. All data are expressed as means (SEMs). Ultrasonic vocalizations were analyzed using a two-factor ANOVA with sex and treatment as fixed factors followed by post hoc pairwise comparisons. Western blot data and the data of noninjected controls were analyzed using Student's $t$ test for independent groups. The maternal retrieval data were analyzed using either the Mann-Whitney $U$ test or Kruskal-Wallis test followed by post hoc testing. All post hoc pairwise comparisons were performed using a Holm's sequential Bonferroni correction to control for familywise error. A regression analysis was performed on the human brain tissue by using the qRT-PCR data and the Western blot data.

\section{Results}

Male and female rat pups were killed on PN4 and Western blots were performed on the cerebellum, amygdala, cortex, thalamus, hypothalamus, hippocampus, and preoptic area (POA) to detect Foxp2 protein. Given seven brain regions and a large number of samples per condition, each brain region was processed individually and, therefore, $t$ tests were performed to compare males and females. Males had significantly higher basal levels of Foxp2 protein than did females in the cerebellum, $\left(t_{(12)}=4.24, p=0.001\right)$, amygdala $\left(t_{(12)}=2.54, p=0.02\right)$, cortex $\left(t_{(10)}=3.23, p=0.01\right)$, and thalamus $\left(t_{(12)}=3.914, p=0.001\right)$ (Fig. $\left.1 A\right)$. There was no sex difference in Foxp2 levels in the hypothalamus or the POA $(P$ values $>0.05)$ and no Foxp2 protein detected in the hippocampus for either sex. Furthermore, there was no sex difference in the amount of protein levels for the closely related Foxp1 in any of the brain regions assessed $(P$ values $>0.05$, Fig. $1 B)$. To determine whether the sex difference in overall Foxp2 protein was a product of different numbers of neurons expressing it, we conducted cell count analysis for Foxp2-immunopositive nuclei in the following brain regions: cortex, amygdala, thalamus, hypothalamus, and cerebellum, but detected no sex differences in any region (data not shown). We conclude that the sex difference is due to a generalized reduction in Foxp2 protein in each cell for females compared with males, with this reduction not being sufficient to impact the detection of Foxp 2 in individual cells by immunohistochemistry quantification (Fig. 1C).

To determine whether there are identifiable sex differences in rat pup ultrasonic distress calls, we recorded and quantified the ultrasonic calls of individual 4 -d-old pups that were separated from the dam for $5 \mathrm{~min}$. Isolated pups made hundreds of calls 
during the separation, with male pups averaging almost twice as many as females. The average duration of individual calls ranged from 60 to $80 \mathrm{~ms}$ but did not vary between males and females. A $2 \times 2$ ANOVA indicated a significant main effect of sex, confirming male pups produced more total vocalizations than females $\left(F_{(1,58)}=8.80, p=0.004\right)$. We also sought to determine the impact of treatment with an siRNA directed against Foxp2 mRNA on pup USVs. Two-way ANOVA indicated a significant interaction between treatment and $\operatorname{sex}\left(F_{(1,58)}=\right.$ 8.73, $p=0.005)$. Control males produced 603 total vocalizations compared with the 350 produced by control females (Fig. $2 A$, post hoc, $p$ values $<0.001)$. In contrast, siRNA-treated males produced 466 total vocalizations, which were significantly fewer than control males (post hoc, $p<$ 0.05). Moreover, siRNA-treated females produced 465 total vocalizations, which was significantly more than the control females (post hoc, $p<0.05$ ). The observed reversed pattern for siRNA-treated females to produce more total vocalizations and for the siRNA-treated males to produce fewer total vocalizations was not a hypothesized outcome.

We also analyzed the fundamental mean frequency of each vocalization. Again there was a significant interaction between sex and treatment $\left(F_{(1,58)}=\right.$ $12.80, p=0.001)$. Control males vocalized at a lower frequency than control females $(p<0.05)$ and treatment with siRNA reversed this pattern such that males treated with siRNA against Foxp2 produced calls that were higher in fre-

quency than control males (Fig. $2 A, p<0.01$ ). In contrast, and unexpectedly, females treated with siRNA produced calls that were lower in frequency than control females (Fig. $2 A, p<0.02$ ).

In addition to quantifying the total number of calls and mean frequency, we also analyzed the mean amplitude of each call produced. Again a significant interaction was observed $\left(F_{(1,58)}=\right.$ $4.20, p=0.04)$ in that control males vocalized at a lower amplitude than control females (Fig. $2 A, p<0.001$ and, siRNA treatment reversed this pattern, but only in the female, such that siRNA-treated females produced vocalizations with lower amplitudes than control females (Fig. $2 A, p<0.01$ ). Figure $2 B$ displays typical sonograms of USVs from each group.

To confirm the ICV injections themselves had no impact on USV production, we analyzed males and females that did not receive any injections. Similar to the treated group, male pups produced more total vocalizations than females $\left(t_{(14)}=3.47, p=\right.$ 0.004 , Fig. $2 C)$ and vocalized at a lower frequency $\left(t_{(14)}=-2.54\right.$, $p=0.02)$, and a lower amplitude $\left(t_{(14)}=-4.05, p=0.001\right)$, than control females (Fig. 2C). Overall, there was no statistically significant deviation in the vocalizations for either the injected or noninjected control males and females on any of the parameters measured; thus, we conclude that control ICV injections did not influence USV production $(F<1, p>0.05)$.

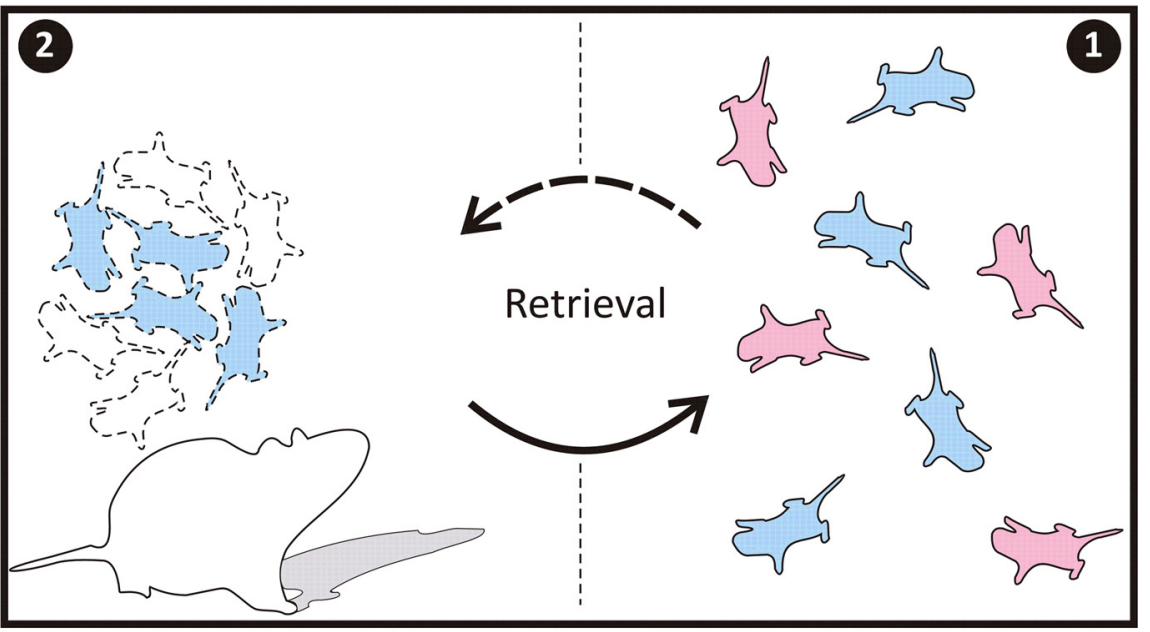

Figure 4. Dams retrieve males before females because of their USVs. Four-day-old pups were removed from the nest for $5 \mathrm{~min}$ and marked to identify sex, then placed back on the opposite side of the home cage as shown in panel 1. The dam retrieved the pups ess likely to be retrieved compared with control males, whereas females treated with Foxp2 siRNA, which have USVs similar to control males (Fig. 1A) were significantly more likely to be retrieved before control females (Kruskal-Wallis test $=20.5, p<0.05$, groups with the same letter are significantly different from each other (C, based on 5 litters).

To evaluate the effectiveness of the siRNA in vivo, we performed a Western blot for Foxp2 on tissues $1 \mathrm{~d}$ after final injection (i.e., PN2). The siRNA treatment reduced Foxp2 protein levels by $\sim 65 \%\left(F_{(1,8)}=26.74, p=0.001\right.$, Fig. $\left.3 A\right)$ but had no impact on the closely related Foxplprotein levels $(F<1.0, p>$ $0.05)$. To further evaluate the effectiveness of the siRNA at reducing protein levels of Foxp2 in neurons, we cultured primary cells from $\mathrm{PN} 0$ rat pups using tissue extracted from the striatum and cortex. In this second confirmation experiment, again, the siRNA treatment was effective in reducing Foxp2 protein levels in the striatum $\left(t_{(8)}=4.61, p=0.002\right)$ as well as in the cortex $\left(t_{(8)}=\right.$ $4.28, p=0.003$, Fig. $3 B$ ). In a third experiment, we sought to determine the duration of the siRNA suppression of Foxp2. Animals were treated on PNO and PN1 as before and assayed on PN4. Once more we observed a sex difference, such that control males had higher Foxp 2 protein levels than females, but there was no longer a difference between siRNA and scrambled control injected males $(F<1.0, p>0.05)$. In contrast, females treated with siRNA had significantly higher Foxp2 protein levels than scrambled control injected females, suggesting a rebound in Foxp2 expression at PN4 following inhibition at PN2 $\left(F_{(1,28)}=\right.$ $4.33, p=0.04)$. Foxp2 protein levels in the siRNA-treated females were increased by almost twice the level compared with scram- 

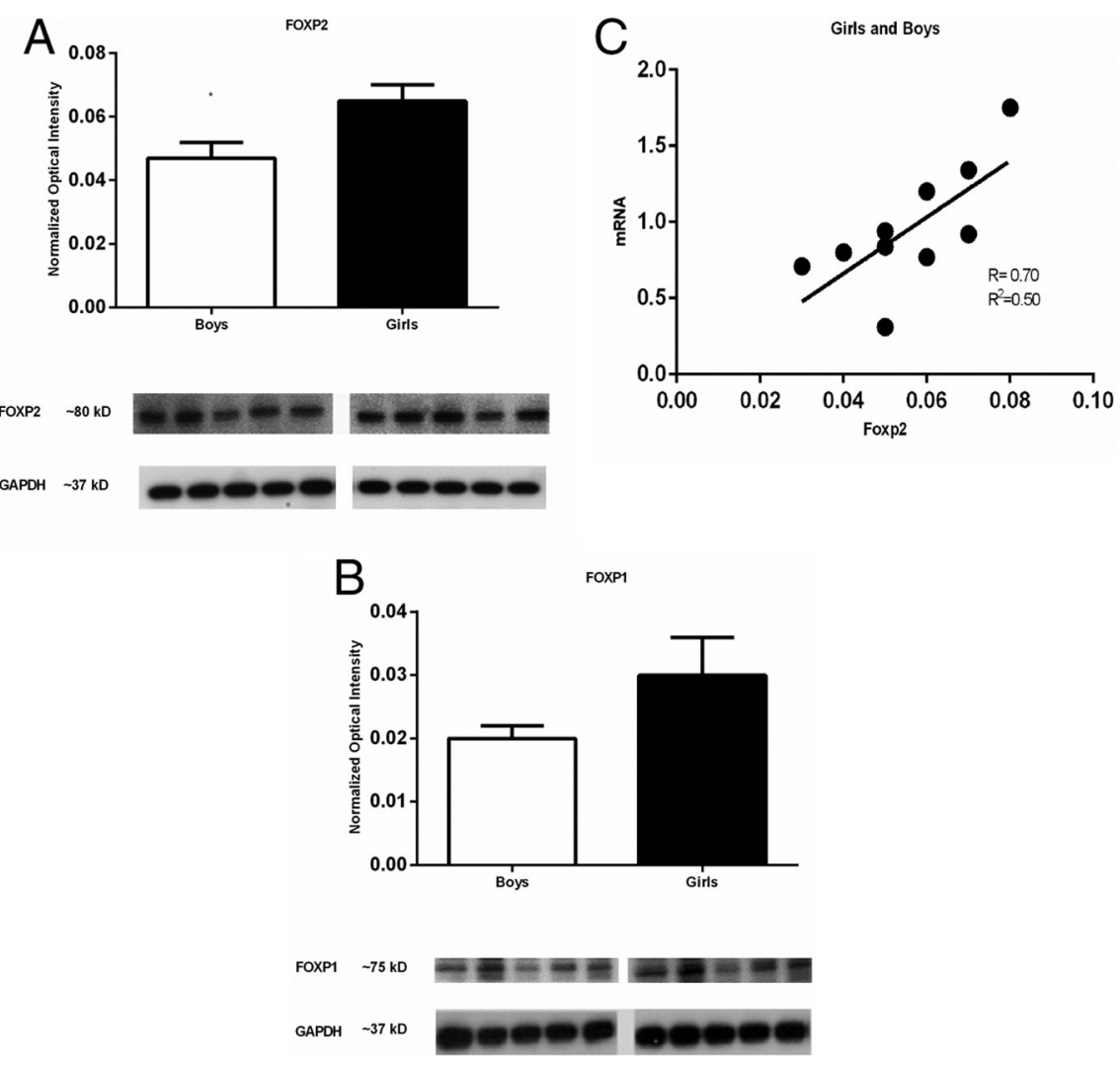

Figure 5. FOXP2 is differentially expressed in boys' versus girls' cortex. Postmortem cortex from the left hemisphere of Brodmann's area 44 from 4-year-old boys and girls were obtained from the NICHD Brain and Tissue Bank, University of Maryland Baltimore. The relative amount of FOXP2 and FOXP1 protein was quantified by Western blot. $A$, Cortex from girls had significantly more FOXP2 than cortex from boys. Data are expressed as mean ( \pm SEM), $n=5 /$ group, significant gender difference $\left({ }^{*} p<0.05\right.$, $t$ test). $\boldsymbol{B}$, In these same samples, there was no sex difference in level of FOXP1 protein. GAPDH indicates loading control. $\boldsymbol{C}$, Regression analysis between protein levels (via Western blot) and mRNA levels for FOXP2 showed a significant positive linear relationship $\left(r=0.70, p=0.02, r^{2}=0.50\right)$.

bled treated control females (post hoc, $p$ values $<0.05$, Fig. $3 C)$.

Rat pups can be scattered from their nest for a variety of reasons, but in the absence of retrieval by the dam, the consequences for the pups are uniformly negative, markedly increasing the risk of death by hypothermia, starvation, dehydration, or predation. Given the consequences of separation from the dam, pups have presumably evolved ways to enhance their retrieval. Based on the higher rate of calling by males, we hypothesized the dam would retrieve males first when displaced from the nest. To test this hypothesis we removed the litter from the nest in the home cage, marked each pup for individual identification and then returned the entire litter to the opposite end of the cage. The sex and treatment condition of each pup were recorded in order of retrieval, resulting in a rank order for each pup based on size of the litter. If there was no sex bias in retrieval, the predicted rank order of return would be the same for both sexes. Observation of control dams, with litters not subject to any treatment, revealed they predominantly retrieved male pups before female, resulting in a significantly lower rank order for male versus female littermates (MannWhitney $U=36.0, p=0.004$, Fig. $4 B$ ).

Because treatment with siRNA against Foxp2 altered the vocalizations of males and females, we were interested to assess how these altered vocalizations would influence maternal retrieval. Post hoc tests following a significant Kruskal-Wallis test, $\left[\chi^{2}\right.$ (3, $N=7)=20.5, p<0.001]$, indicated that control males were retrieved before control females $(p<$ 0.05, Fig. $4 C$ ). Interestingly, there was a significant difference between the female control group and females treated with siRNA. A significant post hoc test showed siRNA-treated females were retrieved before control females ( $p<0.05$, Fig. $4 C$ ). Likewise, control males were retrieved before siRNA-treated males $(p<0.005$, Fig. $4 C$ ). There were no significant differences in the order of retrieval between control males or siRNA-treated females, as well as between control females and siRNA-treated males ( $p$ values $>0.05)$. These results demonstrate pup USV can influence the order of maternal retrieval.

Because normal functioning FOXP2 is important for human language, we obtained human cortex samples from nondiseased donors. The cortex samples were all from the left hemisphere, specifically Brodmann's area 44 . We found females to have higher basal levels of FOXP2 protein than males, $\left(t_{(8)}=2.54, p=0.03\right.$, Fig. $\left.5 A\right)$. There was no gender difference in the amount of protein levels for the closely related FOXP1 $\left(t_{(8)}=1.86, p=0.1\right.$, Fig. $5 B)$. In addition to Western blots we also performed qRT-PCR on these same samples and conducted a correlation/regression analysis between protein levels and mRNA levels for FOXP2. Protein levels positively correlated by linear regression with mRNA levels $\left(r=0.70, p=0.02, r^{2}\right.$ $=0.50$, Fig. $5 C$ ).

\section{Discussion}

The perinatal period is a critical window for the establishment of sex differences in the developing rodent brain (McCarthy and Arnold, 2011). Given the centrality of FoxP2 expression to vocalization in a variety of species, including those that learn speech or song, such as humans and birds, and those in which sound production is considered innate, i.e., mice (Meyer and Zardoya, 2003; Ehret, 2005), we were interested to know whether there were sex differences in Foxp2 protein levels in the brain and found they were higher in males than females. This sex difference was apparent only in areas of the brain associated with higher cognitive functioning, such as the striatum, cortex, thalamus, amygdala and cerebellum, but not in those associated with reproduction, i.e., the POA and hypothalamus. This led us to speculate that different levels of Foxp2 in males and females are one avenue by which sex differences in communication are initiated and/or maintained in the developing brain.

Ultrasonic vocalizations by rodents are considered innate and not learned. Separation or distress calls by neonates clearly communicate to the parent the need to be retrieved and can be modulated as evidenced by the suppression of calling in response to predator detection (Hofer and Shair, 1978; Brudzynski, 2005), or pharmacological treatment with anxiolytics (Vilberg et al., 1984). Selective breeding for high versus low rates of separation-induced USVs by rat pups reveals a genetic underpinning (Brunelli, 2005) that coevolved with associated affective behaviors (Burgdorf et 
al., 2009). Our observation that USVs differ systematically in males and females indicates there is also an innate sex difference. It remains to be determined whether this sex difference is genetically driven or a consequence of differential hormonal exposure during the perinatal sensitive period for establishing sex differences in the brain.

Overall, when isolated from the dam, we found control males had an increased number of total vocalizations, a lower frequency and lower amplitude than control females. Males treated with Foxp2 siRNA had distinctly female-like USVs, with a significantly reduced total number of calls and higher frequency. The phenotype of females in which Foxp2 was reduced was unexpectedly similar to control males, showing an increase in total number of vocalizations, a lower frequency and lower amplitude. The basis of the opposite effects of Foxp2 siRNA in females is unknown but may reflect a rebound and subsequent over shoot in Foxp2 expression due to inhibition starting from a lower baseline, thereby reaching a critical threshold for reactive expression.

In rats, a sex-specific bias in maternal care is evident in the higher rate of anogenital grooming proffered on male pups versus females (Brouette-Lahlou et al., 1992), a behavior driven by testosterone-dependent olfactory cues from the males. To our knowledge, there has been no prior attempt to discern whether dams respond differently to the USV of male versus female pups or whether they preferentially retrieve pups of one sex. Our results showing males were preferentially retrieved over females were surprising but not unexpected, given the clear dissimilarities between male and female vocalizations. There may be advantages for the dam to favor the retrieval of one sex under a given set of conditions, as manipulation of sex ratio in response to environmental conditions is a common strategy used by r-selected species (Trivers and Willard, 1973), i.e., those which produce large numbers of rapidly maturing offspring. Moreover, the fact that siRNA-treated females were preferentially retrieved over siRNAtreated males argues against an olfactory cue mediating the dam's behavior exclusively. Our data suggest that USV in rat pups serves an important communicative role between the dam and her pups. Our hypothesis is further supported by the fact that we also observed anesthetized pups, which do not call, were not retrieved by the dam, further ruling out olfaction as a critical variable. The extent of the communicative meaning of USV on maternal retrieval remains to be elucidated.

The existence of gender differences in human speech and language processing is often reported in the literature but the origins and significance of said differences are highly controversial (for a review see (Wallentin, 2009). There are clear gender differences in the articulation of speech ranging from the acoustic parameters of frequency and pitch to the speed of vocal production (Simpson, 2009). Children typically gesture before they produce their first words (Bates, 1976; Bates et al., 1979; Ozçalişkan and Goldin-Meadow, 2010) and girls, on average, tend to produce their first pointing gestures earlier than boys (Butterworth and Morissette, 1996). Furthermore, language-associated gender differences occur in children, with girls exhibiting a consistent advantage in early language acquisition and development (Bleses et al., 2008). Girls not only produce their first words (Maccoby, 1966) and first sentences (Ramer, 1976) at a younger age than boys, but they also have larger vocabularies (Huttenlocher et al., 1991) and use a greater variety of sentence types (Ramer, 1976) in their early communications than boys of the same age. By the age of four years, children have obtained the basic aptitudes that guide language development over the lifespan (Pinker, 1994). Thus, we analyzed human brain tissues from four year old boys and girls for basal levels of FOXP2 protein. We found boys to have lower levels of FOXP2 protein than girls in the brain region we assessed. This is the opposite direction to the sex difference observed in the rodent, but the meaning of this difference cannot be interpreted until a better understanding of the precise role of FOXP2 in human and animal communication is achieved. However, based on our observations, we postulate higher levels of FOXP2 in girls and higher levels of Foxp2 in male rats is an indication that Foxp 2 protein levels are associated with the more communicative sex. Therefore, we interpret our data to suggest that male rat pups might be more effective communicators using USV, whereas in humans the linguistic advantage of girls is well known. To our knowledge, these findings are the first report of sex or gender differences in FOXP2 expression in animals and humans, with the exception of Hamson et al. (2009), who reported a sex difference in Foxp2 expression in the cerebellum of adult rats. In the present study, we confirm higher Foxp 2 in the cerebellum of males as well as several additional brain regions known to express Foxp2. Moreover, our analysis was on neonatal rats as opposed to adult.

FOXP1 is often associated with FOXP2 and although we failed to detect a sex difference in our rodent model, in humans, we observed a trend toward an increase in FOXP1 for girls over boys. Recently FOXP1 has been associated with language since individuals with variations in FOXP1 exhibit language acquisition delays with the onset of the first word being 3.5 years of age (Horn et al., 2010; O'Roak et al., 2011), and have a working vocabulary of $<100$ words by seven years of age (Horn et al., 2010). In the adult zebra finch males have higher FoxP1 expression than females (Teramitsu et al., 2004), thus FoxP1, like FoxP2 may be associated with the more communicative sex.

Gender is a purely human construct consisting of both self and others' perception of one's sex and is arguably the first and most salient of all phenotypic variables. Sex differences in how language is received and processed and how speech is produced has the potential to influence gender both within and external to an individual. Whether human sex differences in FOXP2, and possibly FOXP1 as well, contribute to gender variation in language is a question for future research.

\section{References}

Amateau SK, McCarthy MM (2002) A novel mechanism of dendritic spine plasticity involving estradiol induction of prostaglandin-E2. J Neurosci 22:8586-8596. Medline

Bates E (1976) Language and context. New York: Academic.

Bates E, Benigni L, Bretherton I, Camaioni L, Volterra V (1979) The emergence of symbols: cognition and communication in infancy. New York: Academic.

Bell SM, Ainsworth MD (1972) Infant crying and maternal responsiveness. Child Dev 43:1171-1190. CrossRef Medline

Bleses D, Vach W, Slott M, Wehberg S, Thomsen P, Madsen TO, Basbøll H (2008) The Danish Communicative Developmental Inventories: validity and main developmental trends. J Child Lang 35:651-669. Medline

Brouette-Lahlou I, Vernet-Maury E, Vigouroux M (1992) Role of pups' ultrasonic calls in a particular maternal behavior in Wistar rat: pups' anogenital licking. Behav Brain Res 50:147-154. CrossRef Medline

Brudzynski SM (2005) Principles of rat communication: quantitative parameters of ultrasonic calls in rats. Behav Genet 35:85-92. CrossRef Medline

Brunelli SA (2005) Selective breeding for an infant phenotype: rat pup ultrasonic vocalization (USV). Behav Genet 35:53-65. CrossRef Medline

Burgdorf J, Panksepp J, Brudzynski SM, Beinfeld MC, Cromwell HC, Kroes RA, Moskal JR (2009) The effects of selective breeding for differential rates of $50 \mathrm{kHz}$ ultrasonic vocalizations on emotional behavior in rats. Dev Psychobiol 51:34-46. CrossRef Medline

Butterworth G, Morissette P (1996) Onset of pointing and the acquisition of language in infancy. J Reprod Infant Psychol 14:219-231. CrossRef 
Ehret G (2005) Infant rodent ultrasounds-a gate to the understanding of sound communication. Behav Genet 35:19-29. CrossRef Medline

Enard W, Przeworski M, Fisher SE, Lai CS, Wiebe V, Kitano T, Monaco AP, Pääbo S (2002) Molecular evolution of FOXP2, a gene involved in speech and language. Nature 418:869-872. CrossRef Medline

Fisher SE, Scharff C (2009) FOXP2 as a molecular window into speech and language. Trends Genet 25:166-177. CrossRef Medline

Haesler S, Rochefort C, Georgi B, Licznerski P, Osten P, Scharff C (2007) Incomplete and inaccurate vocal imitation after knockdown of FoxP2 in songbird basal ganglia nucleus Area X. PLoS Biol 5:e321. CrossRef Medline

Hamson DK, Csupity AS, Gaspar JM, Watson NV (2009) Analysis of Foxp2 expression in the cerebellum reveals a possible sex difference. Neuroreport 20:611-616. CrossRef Medline

Hofer MA, Shair H (1978) Ultrasonic vocalization during social interaction and isolation in 2-weeek-old rats. Dev Psychobiol 11:495-504. CrossRef Medline

Horn D, Kapeller J, Rivera-Brugués N, Moog U, Lorenz-Depiereux B, Eck S, Hempel M, Wagenstaller J, Gawthrope A, Monaco AP, Bonin M, Riess O, Wohlleber E, Illig T, Bezzina CR, Franke A, Spranger S, VillavicencioLorini P, Seifert W, Rosenfeld J, et al. (2010) Identification of FOXP1 deletions in three unrelated patients with mental retardation and significant speech and language deficits. Hum Mutat 31:E1851-E1860. CrossRef Medline

Huttenlocher J Haight W, Bryk A, Seltzer M, Lyons T (1991) Early vocabulary growth: relation to language input and gender. Dev Psychol 27:236248. CrossRef

Kelley DB, Bass AH (2010) Neurobiology of vocal communication: mechanisms for sensorimotor integration and vocal patterning. Curr Opin Neurobiol 20:748-753. CrossRef Medline

Konopka G, Bomar JM, Winden K, Coppola G, Jonsson ZO, Gao F, Peng S, Preuss TM, Wohlschlegel JA, Geschwind DH (2009) Human-specific transcriptional regulation of CNS development genes by FOXP2. Nature 462:213-217. CrossRef Medline

Krause J, Lalueza-Fox C, Orlando L, Enard W, Green RE, Burbano HA, Hublin JJ, Hänni C, Fortea J, de la Rasilla M, Bertranpetit J, Rosas A, Pääbo S (2007) The derived FOXP2 variant of modern humans was shared with Neanderthals. Curr Biol 17:1908-1912. CrossRef Medline

Lai CS, Fisher SE, Hurst JA, Vargha-Khadem F, Monaco AP (2001) A forkhead-domain gene is mutated in a severe speech and language disorder. Nature 413:519-523. CrossRef Medline

Li S, Weidenfeld J, Morrisey EE (2004) Transcriptional and DNA binding activity of the Foxp 1/2/4 family is modulated by heterotypic and homotypic protein interactions. Mol Cell Biol 24:809-822. CrossRef Medline

Maccoby E (1966) The development of sex differences. Stanford, CA: Stanford UP.

MacDermot KD, Bonora E, Sykes N, Coupe AM, Lai CS, Vernes SC, VarghaKhadem F, McKenzie F, Smith RL, Monaco AP, Fisher SE (2005) Identification of FOXP2 truncation as a novel cause of developmental speech and language deficits. Am J Hum Genet 76:1074-1080. CrossRef Medline

McCarthy MM, Arnold AP (2011) Reframing sexual differentiation of the brain. Nat Neurosci 14:677-683. CrossRef Medline
Meyer A, Zardoya R (2003) Recent advances in the (molecular) phylogeny of vertebrates. Annu Rev Ecol Evol Syst 34:311-338. CrossRef

Mukamel Z, Konopka G, Wexler E, Osborn GE, Dong H, Bergman MY, Levitt P, Geschwind DH (2011) Regulation of MET by FOXP2, genes implicated in higher cognitive dysfunction and autism risk. J Neurosci 31: 11437-11442. CrossRef Medline

Newbury DF, Monaco AP (2010) Genetic advances in the study of speech and language disorders. Neuron 68:309-320. CrossRef Medline

Nottebohm F, Arnold AP (1976) Sexual dimorphism in vocal control areas of the songbird brain. Science 194:211-213. CrossRef Medline

O’Roak BJ, Deriziotis P, Lee C, Vives L, Schwartz JJ, Girirajan S, Karakoc E, Mackenzie AP, Ng SB, Baker C, Rieder MJ, Nickerson DA, Bernier R, Fisher SE, Shendure J, Eichler EE (2011) Exome sequencing in sporadic autism spectrum disorders identifies severe de novo mutations. Nat Genet 43:585-589. CrossRef Medline

Ozçalişkan S, Goldin-Meadow S (2010) Sex differences in language first appear in gesture. Dev Sci 13:752-760. CrossRef Medline

Pinker S (1994) The language instinct: how the mind creates language. New York: Harper Perennial.

Ptak SE, Enard W, Wiebe V, Hellmann I, Krause J, Lachmann M, Pääbo S (2009) Linkage disequilibrium extends across putative selected sites in FOXP2. Mol Biol Evol 26:2181-2184. CrossRef Medline

Ramer A (1976) Syntactic styles in emerging language. J Child Lang $3: 49-62$.

Schulz SB, Haesler S, Scharff C, Rochefort C (2010) Knockdown of FoxP2 alters spine density in Area X of the zebra finch. Genes Brain Behav 9:732740. CrossRef Medline

Simpson AP (2009) Phonetic differences between male and female speech. Lang Linguist Compass 3:621-640. CrossRef

Teramitsu I, Kudo LC, London SE, Geschwind DH, White SA (2004) Parallel FoxP1 and FoxP2 expression in songbird and human brain predicts functional interaction. J Neurosci 24:3152-3163. CrossRef Medline

Teramitsu I, Poopatanapong A, Torrisi S, White SA (2010) Striatal FoxP2 is actively regulated during songbird sensorimotor learning. PloS One 5:e8548. CrossRef Medline

Trivers RL, Willard DE (1973) Natural selection of parental ability to vary the sex ratio of offspring. Science 179:90-92. CrossRef Medline

Vernes SC, Newbury DF, Abrahams BS, Winchester L, Nicod J, Groszer M, Alarcón M, Oliver PL, Davies KE, Geschwind DH, Monaco AP, Fisher SE (2008) A functional genetic link between distinct developmental language disorders. N Engl J Med 359:2337-2345. CrossRef Medline

Vernes SC, Oliver PL, Spiteri E, Lockstone HE, Puliyadi R, Taylor JM, Ho J, Mombereau C, Brewer A, Lowy E, Nicod J, Groszer M, Baban D, Sahgal N, Cazier JB, Ragoussis J, Davies KE, Geschwind DH, Fisher SE (2011) Foxp2 regulates gene networks implicated in neurite outgrowth in the developing brain. PLoS Genet 7:e1002145. CrossRef Medline

Vilberg TR, Panksepp J, Kastin AJ, Coy DH (1984) The pharmacology of endorphin modulation of chick distress vocalization. Peptides 5:823-827. CrossRef Medline

Wallentin M (2009) Putative sex differences in verbal abilities and language cortex: a critical review. Brain Lang 108:175-183. CrossRef Medline 